\title{
DISCURSOS (RE)VELADOS: UMA ANÁLISE DIALÓGICA DAS NOVAS DIRETRIZES PARA FORMAÇÃO DOCENTE
}

\author{
DISCOURSES VEILED/REVEALED: \\ A DIALOGICAL ANALYSIS OF THE NEW GUIDELINES \\ TO TEACHER EDUCATION
}

\section{Jozanes Assunção Nunes*}

\section{RESUMO}

Em julho de 2015, o Ministério da Educação aprovou as novas Diretrizes Curriculares Nacionais para a Formação Inicial e Continuada dos Profissionais do Magistério da Educação Básica, revogando as Diretrizes de 2002, instituídas pela Resolução CNE/CP n. 01/2002. Sob a perspectiva da teoria dialógica bakhtiniana, este artigo analisa as relações dialógicas que se engendram no Parecer CNE/CP n. 2/2015, que apresenta as novas Diretrizes, focalizando o posicionamento valorativo dos enunciadores com relação ao discurso da formação para as competências. Examina as relações que o Parecer CNE/CP n. 2/2015 estabelece no diálogo com o Parecer CNE/CP n. 009/2001 - que fundamentou as Diretrizes revogadas, e com os discursos oficiais que tratam da formação para as competências, mobilizados no texto. A análise evidencia que ao mesmo tempo em que o discurso do Parecer CNE/CP n. 2/2015 tenta negar vinculação com o modelo de formação baseado em competências - apagando e substituindo termos a ele relacionados - apresenta grande convergência com as diretrizes revogadas, que tomaram o conceito de competências como nuclear para a formação de professores.

Palavras-chave: Diretrizes Curriculares Nacionais para Formação Docente; Competências; Relações dialógicas.

\section{ABSTRACT}

In July of 2015, the Ministry of Education approved the new National Curricular Guidelines for Initial and Continuing Teacher Education of Elementary and Secondary Education in Brazil, revoking the guidelines of 2002, instituted by the Resolution of the National Council of Education CNE/CP n. 01/2002. Under the perspective of Bakhtinian dialogical theory, this article focuses on the dialogical relations engendered in Regulation CNE/CP n. 2/2015 that presents new guidelines observing the evaluative positioning of enunciators in relation to the discourse of education for competencies. It analyses the dialogical relations that the Regulation CNE/CP n. 2/2015 establishes with the Regulation CNE/CP n. 009/2001 - that supports the revoked guidelines -, and with the official discourses mobilized in the text,

\footnotetext{
* Universidade Federal de Mato Grosso, Cuiabá, MT. Brasil. jozanes@globo.com http://dx.doi.org/10.1590/010318135079180041
} 
which refer to teacher education geared to the competencies. The analysis shows that at the same time the discourse of Regulation CNE/CP n. 2/2015 tries to deny the connection with the model of education based on competencies - erasing and substituting terms related to it - it has great convergence with the revoked guidelines, which took the concept of competencies as the nucleus for teacher education.

Keywords: National Curricular Guidelines for Teacher Education; Competencies; Dialogical relations.

\section{INTRODUÇÃO}

Quatorze anos após a aprovação das Diretrizes Curriculares Nacionais para a Formação de Professores da Educação Básica (DCF), formuladas em 2001 com objetivo de orientar as reformas curriculares nos cursos de licenciatura, o Conselho Nacional de Educação (CNE), em julho de 2015, apresentou à sociedade as novas Diretrizes Curriculares Nacionais para a Formação Inicial e Continuada dos Profissionais do Magistério da Educação Básica (NDCF), estabelecidas pelo Parecer CNE/CP n. 2/2015 e instituídas pela Resolução CNE/CP 2/2015.

Conforme Freitas (2015), a construção das novas Diretrizes responde a antigo anseio de educadores, ao revogar a Resolução que instituiu as DCF, fundamentadas na concepção de competências. De fato, as DCF, apresentadas pelo Parecer CNE/ CP n. 009/2001 e instituídas pela Resolução CNE/CP n. 1/2002, sofreram reiteradas críticas pela comunidade educacional, por trazerem como princípio norteador o ensino por competências. Nesses documentos, a competência é compreendida como a capacidade do professor de mobilizar conhecimentos transformando-os em ação, sendo apresentada como um "paradigma curricular novo" (BRASIL, 2001, p.8) e considerada a base para a formação comum dos professores, assim como para a introdução de uma nova concepção de ensino e de organização curricular.

A elaboração do Parecer CNE/CP n. 2/2015, que apresenta e fundamenta as novas Diretrizes, e a revogação das DCF, instigam-nos a questionar: qual o posicionamento valorativo dos enunciadores do Parecer CNE/CP n. 2/2015 com relação ao discurso da formação para as competências? Há, nas linhas mestras do Parecer, um rompimento com o discurso da formação para as competências? Essas questões vêm carregadas de possibilidades de respostas. Todavia, buscaremos respostas a elas a partir do ponto de vista bakhtiniano, partindo do pressuposto de que, orientado para o seu objeto (as NDCF), o discurso do Parecer CNE/CP n. 2/2015 penetra nesse meio dialogicamente perturbado e tenso de julgamentos e entonações (BAKHIN, 2014) do discurso da formação para as competências.

Nessa direção, neste artigo, analisaremos as relações dialógicas que se engendram no Parecer CNE/CP n. 2/2015, que apresenta as novas Diretrizes, 
focalizando o posicionamento valorativo dos enunciadores com relação ao discurso da formação para as competências. O Parecer faz parte de um conjunto de documentos que compõem o corpus de nossa pesquisa de doutorado, cujo interesse analítico se pauta pela análise dialógica das vozes que constituem o discurso de professores que integram o Núcleo Docente Estruturante de cursos de Letras de uma instituição pública de ensino. A escolha do documento para este estudo se justifica por sua relevância no contexto dos cursos de formação de professores.

Para apresentar a discussão, organizamos este artigo em quatro seções: na primeira, discorremos sobre os conceitos bakhtinianos que sublinharão a análise do Parecer e descrevemos os procedimentos metodológicos de análise; na segunda, ressaltamos a dimensão social e as condições de produção das DCF e NDCF, focalizando o contexto das reformas educacionais em que o conceito de competência foi assumido como organizador do currículo; na terceira, realizamos a análise dialógica do Parecer CNE/CP n. 2/2015 e, por fim, destacamos nossas considerações finais.

\section{POSTULADOS BAKHTINIANOS PARA A ANÁLISE DO PARECER CNE/CP N. $2 / 2015$}

A fundamentação teórico-metodológica deste trabalho insere-se na Teoria/ Análise Dialógica do Discurso - ADD (BRAIT, 2008), advinda de Bakhtin e do Círculo, que toma a interação verbal como o lugar da produção da linguagem e da constituição dos sujeitos. A teoria, como o próprio nome sugere, tem como princípio o dialogismo, considerado essencial para a constituição da linguagem.

Nas palavras de Brait (2012, p. 80), o dialogismo é um princípio que rege a produção e a compreensão dos sentidos, em uma fronteira em que "eu/outro se interdefinem, se interpenetram, sem se fundirem ou se confundirem". Ou seja, é um fenômeno que resume a própria natureza da linguagem imbricada no curso das relações humanas, conservando em seu construto teórico a ideia de que não existe a primeira nem a última palavra, não havendo, desse modo, limites para o contexto dialógico (BAKHTIN, 2011, 410).

Para Bakhtin (2011, p. 371), todo enunciado mantém relação com os discursos anteriores e com os que estão por vir. Não há enunciado isolado. "Um enunciado sempre pressupõe enunciados que o precederam e que o sucederão; ele nunca é o primeiro, nem o último; é apenas o elo de uma cadeia e não pode ser estudado fora dessa cadeia". E dentro dessa perspectiva dialógica, todo enunciado nasce como 
resposta, em virtude de enunciados que lhe precedem, na esteira discursiva que compreende a comunicação verbal, e como interpelação a enunciados futuros. Ou seja, o enunciado nasce a partir de um posicionamento do sujeito discursivo frente a outros enunciados. Nessa ótica, o sujeito discursivo só estará apto a responder se ele se posicionar.

No viés bakhtiano, o papel do outro para quem se constrói o enunciado é de excepcional importância. E esse outro não é um ouvinte passivo, mas participante ativo da comunicação verbal (BAKHTIN, 2011, p. 301). Logo, ao elaborar seu enunciado, o locutor sempre leva em consideração como seu texto será recebido pelo destinatário.

Por sua vez, a compreensão do sentido do enunciado só é possível se o considerarmos em sua relação com outros enunciados, tendo em vista que ele entra em confronto de valores, ideias, posições com enunciados outros, reiterando-os, confirmando-os, completando-os ou rejeitando-os, silenciando-os (BAKHTIN, 2011). Diante disso, neste trabalho, partimos do princípio de que o Parecer CNE/ CP n. 2/2015, objeto deste estudo, é pleno de tonalidades dialógicas e, como tal, não pode ser analisado de modo isolado.

As relações dialógicas traduzem o fato de que o discurso ao se dirigir ao seu objeto, já o encontra contestado, avaliado ou iluminado pelos discursos que já se falaram sobre ele. Assim como nos esclarece Bakhtin (2014, p 86):

Ele se entrelaça com eles em interações complexas, fundindo-se com uns, isolando-se de outros, cruzando com terceiros; e tudo isso pode formar substancialmente o discurso, penetrar em todos os seus estratos semânticos, tornar complexa a sua expressão, influenciar todo o seu aspecto estilístico.

É na dialogia possível da prática que estão inseridos os gêneros do discurso ou os diversos tipos de enunciados, relativamente estáveis do ponto de vista temático, composicional e estilístico, caracterizados pelos contextos nos quais são utilizados. Os gêneros, sob a ótica bakhtiniana, surgem das necessidades comunicativas dos sujeitos e estão diretamente relacionados às diferentes situações sociais. E é por meio deles que os sujeitos interagem nas diferentes esferas da vida em sociedade.

Bakhtin (2011) subdivide os gêneros do discurso em primários (que se constituem em circunstâncias de comunicação verbal espontânea) e secundários (resultado de circunstâncias de comunicação mais complexas). O nosso objeto de análise, o Parecer CNE/CP n. 2/2015, corresponde a um tipo relativamente estável de enunciado caracterizado como gênero discursivo secundário, pertencente a uma esfera social das mais complexas: o Conselho Nacional de Educação (CNE). Essa complexidade recai sobre a configuração dos gêneros nela produzidos: 
Indicação, Parecer e Resolução ${ }^{1}$. No que tange mais especificamente aos Pareceres e às Resoluções, vale pontuar que esses gêneros evidenciam uma temática própria do campo educacional, tratando de regulamentar, num estilo formal, aspectos situacionais, contextuais específicos do sistema de ensino a serem empreendidas conforme determinadas condições histórico-sociais pela comunidade acadêmica ou escolar.

Esses gêneros refletem, assim, as condições específicas e as finalidades da esfera da atividade humana a que estão vinculados: o Conselho Nacional de Educação, que é um órgão colegiado, que a lei atribui o exercício das funções deliberativa e normativa, a fim de interpretar determinados campos da legislação e aplicar as normas a situações específicas (CURY, 2006). Os Pareceres, especificamente os que fundamentam as Diretrizes Curriculares Nacionais, como o que analisamos neste trabalho, por intencionarem tornar comuns os procedimentos a partir dos quais os cursos devem se organizar, convertem-se em dispositivos de regulação social.

Esse aspecto remete a outro prisma da análise dialógica do discurso que é considerar a distinção de duas categorias de palavras: a palavra autoritária e a palavra interiormente persuasiva (BAKHTIN, 2014, p. 142). A primeira, como o nome anuncia, é uma palavra que está associada ao poder, que "ressoa numa alta esfera e não na esfera do contato familiar". É assimilada como uma massa compacta e, por isso, é impermeável, resistente a impregnar-se de outras vozes, a relativizar-se, exigindo "não apenas aspas, mas um destaque mais monumental, por exemplo, uma escrita especial" (BAKHTIN, 2014, p. 143).

A segunda categoria, palavra interiormente persuasiva, carece de autoridade, é desconhecida socialmente e até mesmo privada de legalidade (BAKHTIN, 2014). A palavra persuasiva é metade do autor, metade de outrem, tendo em vista sua natureza aberta, inacabada. No processo de incorporação e transmissão desse tipo de palavra, "diversas vozes alheias lutam pela sua influência sobre a consciência do indivíduo (da mesma maneira que lutam na realidade social ambiente)" (BAKHTIN, 2014, p. 148).

Essas perspectivas se constituem em referenciais importantes no estudo das vozes incorporadas no interior do Parecer CNE/CP n. 2/2015. Tal dimensão dialógica exige uma "investigação das formas usadas na citação do discurso, uma

\footnotetext{
1 A Indicação é um ato propositivo subscrito por um ou mais Conselheiros, contendo sugestão justificada de estudo sobre qualquer matéria de interesse do CNE. O Parecer é um ato enunciativo pelo qual o Conselho Pleno ou qualquer das Câmaras pronuncia-se sobre matéria de sua competência. A Resolução é decorrente de parecer, destinado a estabelecer normas a serem observadas pelos sistemas de ensino sobre matéria de competência do Conselho Pleno ou das Câmaras (CURY, 2006).
} 
vez que essas formas refletem tendências básicas e constantes da recepção ativa do discurso de outrem, e é essa recepção, afinal, que é fundamental também para o diálogo" (BAKHTIN/VOLOCHÍNOV, 2014, p.152, grifos do autor).

Nessa ótica, o processo de apreensão de palavra de outrem não ocorre de modo ingênuo, nem se limita a uma mera transposição de estruturas, mas sim é resultado de compreensão e apreciação dos enunciadores. Ou seja, a palavra de outrem introduzida no contexto do discurso estabelece com o discurso citante "uma amálgama química", em que o "grau de influência mútua do diálogo pode ser imenso" (BAKHTIN, 2014, p. 141). Diante disso, ao estudarmos as formas de transmissão do discurso do outro no Parecer, não podemos "separar os procedimentos de elaboração desse discurso dos procedimentos de seu enquadramento contextual (dialógico)" (BAKHTIN, 2014, p. 141), uma vez que um se relaciona de forma indissolúvel ao outro.

Os conceitos aqui apresentados muito brevemente criarão as condições necessárias para um olhar teoricamente orientado para o nosso objeto de investigação, o discurso do Parecer CNE/CP n. 2/2015, ideologicamente produzido pelo Conselho Nacional de Educação (CNE).

\subsection{Percurso metodológico}

Para análise do Parecer CNE/CP n. 2/2015, que apresenta e fundamenta as Diretrizes Curriculares Nacionais para a Formação Inicial e Continuada dos Profissionais do Magistério da Educação Básica (NDCF), seguimos as orientações do método sociológico de análise proposto por Bakhtin/Volochínov (2014, p. 129), assim como os pressupostos da Teoria/Análise Dialógica do Discurso (BRAIT, 2008) de inspiração bakhtiniana, como anunciamos. Considerar o método sociológico significa compreender a "língua viva" que se dá numa situação histórica, concreta, observando o gênero a que pertence o texto, para, por fim, realizar a análise das "formas da língua na sua interpretação linguística". Isso significa entender, como destaca Brait (2008, p. 13), que o enfrentamento bakhtiniano da linguagem leva em conta também "as particularidades discursivas que apontam para contextos mais amplos, para um extralinguístico aí incluído".

Seguindo esses preceitos, dividimos a seção de análise deste trabalho em duas partes articuladas. Na primeira, discutimos a dimensão social (situação extraverbal) das Diretrizes, destacando o contexto das reformas educacionais em que o conceito de competência foi assumido como nuclear na organização do currículo e as condições de produção do Parecer CNE/CP n. 2/2015. 
$\mathrm{Na}$ segunda parte, examinamos as relações que o Parecer CNE/CP n. 2/2015 estabelece no diálogo com o Parecer CNE/CP n. 009/2001 - que fundamenta as Diretrizes revogadas, e com os discursos oficiais que tratam da formação para as competências, mobilizados no texto. Para análise dessa parte, selecionamos fragmentos nos quais as vozes/ discursos relacionados à formação para as competências estão presentes. Para tanto, recorremos aos mecanismos discursivos e marcadores expressivos que evidenciam a presença de vozes no enunciado, como, por exemplo, o uso de discurso citado, aspas, itálico, entre outros mecanismos que introduzem/marcam as vozes no enunciado.

Selecionamos também os fragmentos nos quais a presença de vozes / discursos não está explicitamente marcada, mas apresentam uma ou mais palavras que remetem a vozes e discursos da formação para as competências. Para isso, recorremos a palavras isoladas ou orações que, neste caso, figuram como "representantes de enunciados plenos" do outro (BAKHTIN, 2011, p. 297), tendo em mente que "enunciados plenos e palavras isoladas podem conservar a sua expressão alheia mas não podem ser reacentuados (em termos de ironia, de indignação, reverência, etc.).

Passemos, então, à discussão do Parecer CNE/CP n.2/2015, que apresenta e fundamenta as NDCF.

\section{DIRETRIZES CURRICULARES DE FORMAÇÃO DOCENTE: DIMENSÃO SOCIAL E CONDIÇÕES DE PRODUÇÃO}

Voloshinov (s.d, p. 10) adverte que "quando cortarmos o enunciado do solo real que o nutre, perdemos a chave tanto de sua forma quanto de seu conteúdo". Atentos a essa questão, nesta seção, discutiremos, inicialmente, alguns aspectos relacionados ao contexto das reformas curriculares que levaram as Diretrizes Curriculares Nacionais de Formação de Professores para a Educação Básica (DCF), produzidas em 2001, a incorporarem o conceito de competências, para, após, chegarmos à situação de produção mais imediata do Parecer CNE/CP n. 2/2015, que apresenta e fundamenta as novas Diretrizes Curriculares Nacionais para a Formação Inicial e Continuada dos Profissionais do Magistério da Educação Básica (NDCF).

As DCF e NDCF foram produzidas pelos conselheiros do Conselho Nacional de Educação (CNE), órgão colegiado integrante do Ministério da Educação, que tem, hoje, a função de estabelecer normas congruentes com a legislação em vigor para a Educação Básica e Educação Superior. Ao realizar a mediação entre a sociedade 
civil organizada e os organismos governamentais, o CNE se constitui como esfera ideológica de poder e de controle social, cujo discurso político-educacional se materializa sob várias roupagens, com intenções e finalidades distintas. $\mathrm{O}$ órgão se estabelece a partir de reuniões colegiadas das quais resultam os pareceres, gêneros que materializam em ato a potência do Estado, contida na norma, em vista do interesse público.

Em 2001, para atender à Lei de Diretrizes e Bases (LDB) de 1996, que atribui às universidades a competência de fixar os currículos dos seus cursos, observadas as diretrizes gerais pertinentes, o CNE, por meio do Parecer n. 09/2001 e Resolução n. 01/2002, instituiu as DCF, num contexto de intensos debates sobre diplomas e perfis profissionais devido às transformações na sociedade e, principalmente, no processo de trabalho.

O processo de reforma curricular decorrente da promulgação da LDB se coaduna não só ao contexto local brasileiro, mas também resulta da influência de organismos internacionais que, por meio de uma vasta documentação (relatórios, boletins, recomendações, acordos, tratados, etc.), propalou o discurso de que a educação melhora o desempenho no trabalho e de que sua expansão potencializa o crescimento.

Nesse contexto, instituições como a Organização dos Estados Americanos OEA -, Banco Interamericano de Desenvolvimento - BID -, Banco Mundial - BM -, Organização de Cooperação e Desenvolvimento Econômico-OCDE, entre outros, passaram a determinar as metas que os países deviam atingir, também em matéria de educação. "Assim é que alguns organismos assumiram de forma velada o papel dos ministérios de educação, sobretudo no caso dos países em desenvolvimento". (MAUÉS, 2003, p. 93). Ou seja, esses interlocutores passaram a exercer influência na elaboração e consolidação das políticas educacionais, mediante regulação como ajustamento propositivo, com regras e normas a serem executadas pela educação.

A Organização das Nações Unidas para a Educação, a Ciência e a Cultura (UNESCO) também outorgou lugar de destaque no processo de reforma da educação brasileira (SHIROMA, 2011). Nessa ótica, destacamos a importância do relatório formulado pela UNESCO, conhecido como Relatório Jacques Delors (DELORS, 1998), que se fundamenta no conceito de competências e indica quatro grandes necessidades de aprendizagem ou os quatro pilares da educação: aprender a conhecer; aprender a fazer; aprender a viver junto e aprender a ser. Tais perspectivas refletiram-se no Brasil que seguiu a tendência de introduzir o conceito de competência nas reformas educacionais, tendo como fundamento os princípios axiológicos expostos nos respectivos pilares. 
Nessa mesma direção de valoração da noção de competências, a OCDE conforme Maués (2011, p. 77), passou a dar destaque à educação quando percebeu nela uma forma de valorização do capital humano, com vistas a "desenvolver as competências e as atitudes que são essenciais para o crescimento econômico, a promoção individual e a redução das desigualdades" (grifos nossos).

Desse modo, tocando os "milhares de fios dialógicos" (BAKHTIN, 2011) existentes no contexto da reforma curricular brasileira, as DCF passaram a assumir as competências como conceito organizador do currículo, entendidas como nucleares na orientação dos cursos de formação de professores (BRASIL, 2001).

Perrenoud (2000, p. 13), um dos autores que inspirou as DCF (como poderemos constatar na seção seguinte), define competência como sendo a "capacidade de mobilizar diversos recursos cognitivos para enfrentar um tipo de situação". O autor explica que a definição compreende os seguintes aspectos:

1. As competências não são elas mesmas saberes, savoir-faire ou atitudes, mas mobilizam, integram e orquestram tais recursos; 2 . Essa mobilização só é pertinente em situação, sendo cada situação singular, mesmo que se possa tratá-la em analogia com outra, já encontrada; 3 . O exercício da competência passa por operações mentais complexas, subentendidas por esquemas de pensamento $[\ldots]$; 4. As competências profissionais constroem-se, em formação, mas também ao sabor da navegação diária de um professor [...]. (PERRENOUD, 2000, pp. 13-14, grifos do autor)

Notamos que as perspectivas apresentadas no excerto apontam para compreensão da competência como incorporação e mobilização de conhecimento para a ação - savoir-faire, pressupondo uma construção pessoal, singular do sujeito em determinada situação por ele enfrentada.

Não obstante, o conceito de competência tem sofrido duras críticas por estar associado a políticas educacionais vinculadas ao apoio financeiro de agentes internacionais. Além disso, nas DCF, a crítica recai sobre seu perfil instrumentaltecnicista, que supervaloriza o pragmatismo praticista em detrimento da reflexão teórica e filosófica da educação. Nesse tocante, merecem destaque as posições da Associação Nacional pela Formação de Profissionais da Educação (ANFOPE, 2001), que contrariamente à concepção de competência defendida no Parecer CNE/CP n. 009/2001, que fundamenta as DCF, assim se manifesta:

\footnotetext{
A luta pela formação teórica de qualidade, um dos pilares fundamentais da base comum nacional, implica recuperar, nas reformulações curriculares, a importância do espaço para análise da educação enquanto disciplina, seus campos de estudo, métodos de estudo e status epistemológico; busca ainda a compreensão da totalidade do processo de trabalho docente e nos unifica na luta contra as tentativas de aligeiramento da formação do profissional da Educação,
} 
via propostas neo-tecnicistas que pretendem transforma-lo em um "prático" com competência para lidar exclusivamente com os problemas concretos de sua prática cotidiana. (ANFOPE, 2001, p. 4, grifos nossos)

Após quatorze anos orientando a construção dos currículos dos cursos de licenciatura, as DCF são revogadas, entrando em vigor, em 2015, as NDCF, apresentadas e fundamentadas pelo Parecer CNE/CP n. 2/2015.

Conforme o próprio Parecer, em 2004, o CNE criou a Comissão Bicameral de Formação de Professores, formada por conselheiros da Câmara de Educação Superior e da Câmara de Educação Básica, com a finalidade de desenvolver estudos e proposições sobre formação de profissionais do magistério da educação básica que "tem se constituído em campo de disputas de concepções, dinâmicas, políticas, currículos, entre outros" (BRASIL, 2015).

A Comissão, em função da renovação periódica dos membros do CNE, foi várias vezes recomposta até que em 2014 os novos membros, retomando os estudos das comissões anteriores definiram como horizonte propositivo de sua atuação a discussão e a proposição das NDCF. A versão de documento base e proposta de minuta das Diretrizes foram submetidas para discussão pública, envolvendo reuniões ampliadas, debates e participação em eventos sobre a temática. As rodadas de discussões, ao longo de 2014, propiciaram críticas e sugestões, por meio de debates no CNE e em outros espaços em que os conselheiros da Comissão Bicameral do CNE foram convidados. No dia 9 de junho de 2015, o Parecer foi aprovado pelo Conselho Pleno (CP) do Conselho Nacional de Educação (CNE) e homologado pelo Ministério da Educação (MEC) em 24 de junho de 2015.

$\mathrm{O}$ processo de debate entre os conselheiros e representantes de órgãos e entidades diversos evidencia a preocupação do $\mathrm{CNE}$ em demarcar o caráter participativo na delimitação das novas Diretrizes, objetivando atribuir legitimidade ao documento produzido. Essa dinâmica implica reconhecer as novas Diretrizes como espaço marcado pela interseção de diferentes vozes, e também pela convivência, tensa por natureza (BAKHTIN, 2014), de diferentes discursos que disputam a hegemonia para a formação de professores.

É certo que os integrantes da comissão responsável pela elaboração do Parecer selecionaram as contribuições recebidas, com base em suas apreciações valorativas. Bakhtin (s.d, p. 87) esclarece isso ao explicar que "nenhum conteúdo seria realizado, nenhum pensamento seria realmente pensado, se não se estabelecesse um vínculo essencial entre o conteúdo e o seu tom emotivo-volitivo, isto é, o seu valor realmente afirmado por aquele que pensa". Nesse processo, o CNE foi efetivando seu papel, buscando cumprir uma de suas mais proeminentes missões que é a elaboração e a aprovação de Diretrizes, no caso, as NDCF. 
Além de ser uma resposta aos diversos estudos e pesquisas que "apontam para a necessidade de se repensar a formação docente" (BRASIL, 2015, p. 21), o Parecer CNE/CP n. 2/2015 é, também, uma resposta aos acontecimentos que ocorreram no espaço-tempo de sua produção, entre os quais destacamos: a aprovação da Emenda Constitucional 59/2009 que, dentre outras determinações, ampliou a educação obrigatória do ensino fundamental para educação de 4 a 17 anos; a realização de diversas conferências nacionais de educação, como políticas e movimentos que avançaram no entendimento da valorização dos profissionais da educação como resultante da efetiva articulação entre formação inicial e continuada; e, mais recentemente, a aprovação do Plano Nacional de Educação -2014 (BRASIL, 2015).

Tais acontecimentos implicaram o repensar e o avançar nos marcos referenciais atuais para a formação inicial e continuada, "por meio de ações mais orgânicas entre as políticas e a gestão para educação básica e a educação superior" (BRASIL, 2015, p. 22). Orientados pelo pensamento bakhtiniano, entendemos que o Parecer CNE/ CP n. 2/2015 reflete esses acontecimentos ao mesmo tempo que os refrata, uma vez que corresponde a uma tomada de posição dos enunciadores a respeito daquilo que enuncia (BAKHTIN/VOLOCHÍNOV, 2014).

A busca por organicidade na formação inicial e continuada de professores evidencia o interesse do CNE em integrar a educação superior à educação básica de tal modo que a formação dos professores passe a ser uma atribuição não apenas das instituições de ensino superior, mas uma parceria com a educação básica. Nesse sentido, as NDCF são orientadas para os membros das comunidades acadêmica e escolar, reais interlocutores da interação discursiva.

Enfim, segundo a concepção bakhtiniana, frente a qualquer enunciado, assumimos uma postura ativamente responsiva. Essa resposta pode ser de concordância ou discordância, aceitação ou negação, etc. Assim sendo, a resposta ou o posicionamento valorativo dos enunciadores do Parecer CNE/CP n. 2/2015 em relação ao discurso das competências que sustenta as Diretrizes de 2001, revogadas em 2015, é o que analisaremos na seção seguinte.

\section{ANÁLISE EM PERSPECTIVA DIALÓGICA DO PARECER CNE/CP N. 2/2015}

O Parecer CNE/CP 02/2015 é composto por sessenta e uma páginas e está dividido em duas partes. Na primeira, intitulada Relatório, há uma profunda contextualização para justificar a necessidade de alteração das Diretrizes 
Curriculares para formação de professores. Na segunda, denominada Diretrizes curriculares nacionais para a formação inicial e continuada dos profissionais do magistério: proposição, os enunciadores apresentam princípios orientadores amplos, bem como diretrizes para uma política de formação inicial e continuada dos profissionais do magistério, para sua organização no tempo e espaço e para a estruturação dos cursos. Após, há o Voto da Comissão que aprova o Parecer e o Projeto de Resolução anexo ao documento, seguido da Decisão do Conselho Pleno que aprova, por unanimidade, o voto da Comissão.

Ao proceder à leitura global do documento, verificamos, sem muito esforço, que, no discurso dos enunciadores, há omissões de expressões, relacionadas ao paradigma das competências, que marcam os textos curriculares produzidos no contexto da reforma da política curricular que ocorreu a partir da segunda metade da década de 1990. Não há, por exemplo, proposições como "constituição de competências"; "desenvolvimento de competências"; "aquisição de competências"; "aprendizagem por competências"; "avaliar as competências" entre outras, que são repetidas inúmeras vezes nos discursos oficiais que normatizam os cursos de licenciatura desde 2001.

A refração pode ser percebida também na substituição do termo "competência" do par "competências e habilidades", amplamente utilizado nos textos curriculares oficiais por quase uma década e meia. O termo foi substituído por "informações" em algumas situações e, em outras, "conhecimentos":

$\mathrm{O}$ (A) egresso(a) da formação inicial e continuada deverá possuir um repertório de informações e babilidades. (BRASIL, 2015, p. 25, grifos nossos)

Considerando a identidade do profissional do magistério da educação básica proposta, deverá ser garantida, ao longo do processo, efetiva e concomitante relação entre teoria e prática, ambas fornecendo elementos básicos para o desenvolvimento dos conbecimentos e babilidades necessários à docência. (BRASIL, 2015, pp. 30-31, grifos nossos)

Constata-se aí a instituição de uma relação polêmica, na superfície do texto, com relação ao uso do termo competência. Bakhtin (2011) nos explica que ao elaborar seu enunciado, o sujeito discursivo sempre leva em consideração como seu texto será recebido pelo destinatário. Considerando esse aspecto, ele atua conscientemente na escolha dos procedimentos composicionais e dos recursos linguísticos. Sabemos que as DCF sofreram críticas severas na esfera educacional por serem centradas na noção de competência. Ao excluírem os termos ligados ao paradigma das competências, percebemos a preocupação dos enunciadores do 
Parecer CNE/CP n. 2/2015 com a recepção da sua proposta de formação docente, buscando não associá-la ao modelo de formação criticado e revogado.

Essa situação nos motiva a investigar, com olhar bakhtiniano, se, de fato, os enunciadores do Parecer CNE/CP romperam com o discurso da formação para as competências em seu discurso. Para suscitar uma resposta, num primeiro momento, estabeleceremos relações dialógicas entre o Parecer CNE/CP n. 2/2015 e o Parecer CNE/CP n. 009/2001, que fundamenta as Diretrizes Curriculares Nacionais para Formação de Professores (DCF), em que o conceito nuclear da intervenção pedagógica pretendida dos sujeitos discursivos do documento é o de competência.

Como foco de análise, priorizaremos o item 2.2 da segunda parte do Parecer CNE/CP n. 2/2015, por tratar do egresso da formação inicial e continuada, olhando-o do ponto de vista discursivo. Num segundo momento, faremos a análise dos discursos oficiais que tratam da formação para as competências, convocados pelos enunciadores para explicar aspectos do modelo de formação proposto.

\subsection{Diálogos com o Parecer CNE/CP n. 009/2001}

A despeito de haver grande dificuldade para conceituar competência, no Parecer CNE/CP n. 009/2001, esta é definida como capacidade de mobilizar e colocar em ação conhecimentos necessários para o desempenho das atividades requeridas pela natureza do trabalho:

\footnotetext{
As competências tratam sempre de alguma forma de atuação, só existem "em situação" e, portanto, não podem ser aprendidas apenas no plano teórico nem no estritamente prático. A aprendizagem por competências permite a articulação entre teoria e prática e supera a tradicional dicotomia entre essas duas dimensões, definindo-se pela capacidade de mobilizar múltiplos recursos numa mesma situação, entre os quais os conhecimentos adquiridos na reflexão sobre as questões pedagógicas e aqueles construídos na vida profissional e pessoal, para responder às diferentes demandas das situações de trabalho. (BRASIL, 2001, p. 30)
}

Como se pode depreender, a definição dialoga com o pensamento de Perrenoud (2000), conforme abordamos na seção anterior, para quem a competência é entendida como um saber em ação. Isto é, a competência manifesta-se na ação, num contexto específico, tratando-se de alguma forma de atuação que só existe "em situação".

Com o intuito de averiguar se as vozes presentes no excerto em análise ecoam no Parecer CNE/CP n. 2/2015, focalizamos o enunciado que trata das características e dimensões da iniciação à docência que devem constar nos Projetos 
Pedagógicos dos Cursos, constante do item 2.2 "Egresso da formação inicial e continuada". Nesse item, os enunciadores assim se posicionam:

(...) o PPC, em articulação com o PPI e o PDI, deve abranger diferentes características e dimensões da iniciação à docência, entre as quais:

I - estudo do contexto educacional, envolvendo ações nos diferentes espaços escolares, como salas de aula, laboratórios, bibliotecas, espaços recreativos e desportivos, ateliês, secretarias; II - desenvolvimento de ações que valorizem o trabalho coletivo, interdisciplinar e com intencionalidade pedagógica clara para o ensino e o processo de ensinoaprendizagem;

III - planejamento e execução de atividades nos espaços formativos (instituições de educação básica e de educação superior, agregando outros ambientes culturais, científicos e tecnológicos, físicos e virtuais que ampliem as oportunidades de construção de conbecimento), desenvolvidas em níveis crescentes de complexidade em direção à autonomia do estudante em formação;

IV - participação nas atividades de planejamento e no projeto pedagógico da escola, bem como nas reuniōes pedagógicas e órgãos colegiados

$\mathrm{V}$ - análise do processo pedagógico e de ensino-aprendizagem dos conteúdos específicos e pedagógicos, além das diretrizes e currículos educacionais da educação básica;

VI - leitura e discussão de referenciais teóricos contemporâneos educacionais e de formação para a compreensão e a apresentação de propostas e dinâmicas didáticopedagógicas;

VII - cotejamento e análise de conteúdos que balizam e fundamentam as diretrizes curriculares para a educação básica, bem como de conhecimentos específicos e pedagógicos, concepções e dinâmicas didático-pedagógicas, articuladas à prática e à experiência dos professores das escolas de educação básica, seus saberes sobre a escola e sobre a mediação didática dos conteńdos,

VIII - desenvolvimento, execução, acompanbamento e avaliação de projetos educacionais e escolares, incluindo o uso de tecnologias educacionais, diferentes recursos e estratégias didáticopedagógicas;

IX - sistematização e registro das atividades em portfólio ou recurso pedagógico equivalente de acompanhamento (BRASIL, 2015, pp. 25-26, grifos nossos).

No excerto, constatamos, na linha do que enfatiza Bakhtin (2014, p. 86), que entre o discurso do Parecer de 2015 e seu objeto (as NDCF) interpõem-se discursos do Parecer de 2001. Desse modo, o objeto "está amarrado e penetrado 
por ideias gerais, por pontos de vista, por apreciações" do discurso do Parecer $\mathrm{CNE} / \mathrm{CP}$ n. 009/2001, de tal forma que conseguimos perceber a convergência e sintonia quanto ao entendimento de competência como algo que se constrói "em situação", "na ação".

A confirmação dessa percepção está explícita nas inúmeras iniciativas voltadas para dentro da escola, conforme observamos nos fragmentos: "estudo do contexto educacional, envolvendo ações nos diferentes espaços escolares"; "execução de atividades nos espaços formativos"; "participação nas atividades de planejamento e no projeto pedagógico da escola, bem como nas reuniões pedagógicas e órgãos colegiados"; "desenvolvimento, execução, acompanhamento e avaliação de projetos educacionais e escolares".

Tais ações, que devem ser descritas nos Projetos Pedagógicos dos Cursos de formação de professores, referem-se às intervenções dos sujeitos em situações específicas, cuja compreensão está em sintonia com a concepção de competências que, conforme vimos no fragmento extraído do Parecer CNE/CP n. 009/2001, "tratam sempre de alguma forma de atuação", existindo "em situação", se definindo "pela capacidade de mobilizar múltiplos recursos" para responder às exigências das situações de trabalho.

Nesse sentido, além de os enunciadores incorporarem em seu texto a ideia contida no conceito de competência expresso no Parecer de 2001, como conhecimento construído na e pela experiência, "em situação", acabam incorporando também (pelo menos em parte) o conceito da "simetria invertida" presente no mesmo Parecer.

Articulado à noção de competência, o conceito de simetria invertida é marcado pelo entendimento de que o preparo do professor deve ocorrer em lugar similar àquele em que ele irá atuar. Sob essa perspectiva, a realidade concreta dos sujeitos da esfera escolar, sua organização e gestão, os projetos e cursos de formação deverão ser contextualizados no espaço e no tempo daquela esfera. Os princípios básicos da formação docente que o conceito de simetria invertida evoca, como, planejar, analisar e participar de situações próprias da docência em sala de aula e do trabalho pedagógico na escola estão presentes no fragmento em análise, marcando, assim, consonâncias dialógicas entre os dois pareceres, apesar de o novo Parecer não mencionar o conceito.

Todavia, faz-se importante destacar que esse mesmo princípio vem acompanhado da ideia de que os currículos dos cursos de licenciatura devem tornar a educação do professor em formação "uma experiência análoga à experiência de aprendizagem que ele deve facilitar aos seus futuros alunos" (BRASIL, 2001, 
p. 31). Ou seja, o professor em formação precisa experimentar, como aluno, o que irá desenvolver na sua atuação profissional. Na orientação das NDCF, como podemos constatar no excerto, o licenciando ao invés de vivenciar o papel de aluno, aprendendo conteúdos definidos para a educação básica, como sugere as DCF, deverá "cotejar" e "analisar" esses conteúdos, assim como os "conhecimentos específicos e pedagógicos, concepções e dinâmicas didático-pedagógicas" relacionadas a experiências dos professores da educação básica. No entanto, nessa nova orientação, verificamos vestígios da simetria invertida, num diálogo tenso, apesar de só aparecer a voz das NDCF.

Na globalidade do Parecer CNE/CP n. 2/2015, permanece a ideia de que o preparo do futuro professor deve envolver ações nos diferentes espaços escolares, em concordância com o que está prescrito no Parecer de 2001. Ou seja, o termo "simetria invertida", intimamente ligado ao conceito de "competência", não é pronunciado nas NDCF, mas o seu princípio permanece vivo com uma nova roupagem. Assim, percebe-se no discurso das novas Diretrizes um dialogismo velado, visto que "cada uma das palavras presentes responde e reage com todas as suas fibras ao interlocutor invisível, sugerindo fora de si, além dos seus limites, a palavra não pronunciada do outro" (BAKHTIN, 2013, p.226).

No Parecer CNE/CP n. 009/2001, a partir da concepção de competência definida, os enunciadores definem um conjunto de "Competências a serem desenvolvidas na formação da educação básica": (i) competências referentes ao comprometimento com os valores inspiradores da sociedade democrática; (ii) competências referentes à compreensão do papel social da escola ; (iii) competências referentes ao domínio dos conteúdos a serem socializados, de seus significados em diferentes contextos e de sua articulação interdisciplinar; (iv) competências referentes ao domínio do conhecimento pedagógico; (v) competências referentes ao conhecimento de processos de investigação que possibilitem o aperfeiçoamento da prática pedagógica; (vi) competências referentes ao gerenciamento do próprio desenvolvimento profissional.

Com intuito de orientar as Instituições de Ensino Superior (IES) na elaboração dos seus Projetos Pedagógicos, os enunciadores do Parecer apresentam uma série de itens que explicitam cada uma das competências definidas (BRASIL, 2001).

$\mathrm{Na}$ análise do Parecer CNE/CP n. 2/2015, ao examinar a descrição do perfil almejado para o egresso, do item "Egresso da formação inicial e continuada", observamos que alguns princípios evidenciados no conjunto das competências definidas no Parecer de 2001 foram reenunciados, ainda que no discurso dos enunciadores não tenha sido mencionado o termo «competência». Na tabela 
1, apresentamos, de um lado, fragmentos do Parecer de 2015, que tratam do desempenho esperado dos egressos, e, de outro, alguns itens do conjunto de competências definidas no Parecer CNE/CP n. 009/2001, a fim de que possamos analisar o diálogo travado entre os dois Pareceres.

\section{Tabela 1 - Discursos dos Pareceres CNE/CP n. 2/2015 e n. 009/2001}

\begin{tabular}{|c|c|}
\hline $\begin{array}{l}\text { Fragmentos extraídos do Parecer CNE/CP n. } \\
2 / 2015\end{array}$ & $\begin{array}{l}\text { Fragmentos extraídos do Parecer CNE/CP } n \text {. } \\
009 / 2001^{2}\end{array}$ \\
\hline $\begin{array}{l}\text { A concepção de formação assinalada, bem como a sua efetiva } \\
\text { institucionalização pelas instituições formadoras, busca ga- } \\
\text { rantir que o (a) egresso (a) dos cursos de formação inicial em } \\
\text { nivel superior deverá, portanto, estar apto a: }\end{array}$ & $\begin{array}{l}\text { Competências a serem desenvolvidas na formação da edu- } \\
\text { cação básica } \\
\text { (...) }\end{array}$ \\
\hline $\begin{array}{l}\text { (1) atuar com ética e compromisso com vistas à construção de } \\
\text { uma sociedade justa, equânime, igualitária }\end{array}$ & $\begin{array}{l}\text { (1) Pautar-se por princípios da ética democrática: dig- } \\
\text { nidade bumana, justiça, respeito mútuo, participaçãa, } \\
\text { responsabilidade, diálogo e solidariedade, para atuação } \\
\text { como profissionais e como cidadãos (Competências } \\
\text { referentes ao comprometimento com os va- } \\
\text { lores inspiradores da sociedade democrática) }\end{array}$ \\
\hline $\begin{array}{l}\text { (2) dominar os conteúdos específicos e pedagógicos e as abor- } \\
\text { dagens teórico-metodológicas do seu ensino, de forma inter- } \\
\text { disciplinar e adeduada às diferentes fases do desenvolvimento } \\
\text { bumano; }\end{array}$ & $\begin{array}{l}\text { (2) Conbecer edominar os conteúdos básicos relacionados } \\
\text { às áreas/disciplinas de conbecimento que serão objeto da } \\
\text { atividade docente, adequando-os às atividades escolares } \\
\text { próprias das diferentes etapas e modalidades da educação } \\
\text { básica. (Competências referentes ao domínio } \\
\text { dos conteúdos a serem socializados, de seus } \\
\text { significados em diferentes contextos e de sua } \\
\text { articulação interdisciplinar) }\end{array}$ \\
\hline $\begin{array}{l}\text { (3) relacionar a linguagem dos meios de comunicação à } \\
\text { educação, nos processos didático-pedagógicos, demonstrando } \\
\text { dominio das tecnologias de informação e comunicação para o } \\
\text { desenvolvimento da aprendizagem; }\end{array}$ & $\begin{array}{l}\text { (3) Fazer uso de recursos da tecnologia da informação e da } \\
\text { comunicação de forma } \\
\text { a aumentar as possibilidades de aprendizagem dos alunos } \\
\text { (Competências referentes ao domínio dos con- } \\
\text { teúdos a serem socializados, de seus significa- } \\
\text { dos em diferentes contextos e de sua articula- } \\
\text { ção interdisciplinar) }\end{array}$ \\
\hline $\begin{array}{l}\text { (4) promover e facilitar relações de cooperação entre a insti- } \\
\text { tuição educativa, a familia e a comunidade; }\end{array}$ & $\begin{array}{l}\text { (4) Estabelecer relações de parceria e colaboração com os } \\
\text { pais dos alunos, de modo a promover sua participação na } \\
\text { comunidade escolar e a comunicação entre eles e a escola } \\
\text { (Competências referentes à compreensão do } \\
\text { papel social da escola). }\end{array}$ \\
\hline
\end{tabular}

2 Apresentamos aqui apenas alguns dos itens que explicitam cada uma das competências definidas pelo parecer. 
(5) demonstrar consciência da diversidade, respeitando as diferenças de natureza ambiental-ecológica, étnico-racial, de gêneros, de faixas geracionais, de classes sociais, religiosas, de necessidades especiais, de diversidade sexual, entre outras;

(6) atuar na gestão e organização das instituições de educação básica, planejando, executando, acompanbando e avaliando políticas, projetos e programas educacionais;

- participar na gestão das instituições de educação básica, contribuindo para a elaboração, implementação, coordenação, acompanbamento e avaliação do projeto pedagógico;

(7) realizar pesquisas que proporcionem conbecimento sobre os estudantes e sua realidade sociocultural; sobre processos de ensinar e de aprender, em diferentes meios ambiental-ecológicos; sobre propostas curriculares, e sobre organização do trabalho educativo e práticas pedagógicas, entre outros;

- utilizar instrumentos de pesquisa adequados para a construção de conbecimentos pedagógicos e científicos, objetivando a reflexão sobre a própria prática e a discussão e disseminação desses conbecimentos.
(5) Reconbecer e respeitar a diversidade manifestada por seus alunos, em seus aspectos sociais, culturais e físicos, detectando e combatendo todas as formas de discriminação (Competências referentes ao comprometimento com os valores inspiradores da sociedade democrática).

(6) Participar coletiva e cooperativamente da elaboração, gestão, desenvolvimento e avaliação do projeto educativo e curricular da escola, atuando em diferentes contextos da prática profissional, além da sala de aula (Competências referentes à compreensão do papel social da escola)

(7) Utilizar resultados de pesquisa para o aprimoramento de sua prática profissional. (Competências referentes ao conhecimento de processos de investigação que possibilitem o aperfeiçoamento da prática pedagógica)

A despeito de o Parecer CNE/CP n. 2/2015 estabelecer o perfil desejado do egresso e o Parecer CNE/CP n. 009/2001 apresentar as competências necessárias ao professor que irá atuar na educação básica (o que não deixa de ser um delineamento do perfil profissional desejado), constata-se na tabela que ambos apresentam pontos convergentes tanto no plano estrutural, quanto no plano do conteúdo. Quanto à estrutura, um aspecto convergente é que ambos enunciados estão conformados em forma de lista, iniciando-se com um verbo. No que tange ao conteúdo abordado, tanto o Parecer de 2015, quanto o de 2001 evidenciam uma preocupação com os resultados a serem obtidos ao final da formação do professor, com a institucionalização do modelo de formação proposto, além de tenderem para uma mesma orientação valorativa quanto aos temas abordados.

Nessa direção, um aspecto que merece destaque é o uso do adjetivo "apto" no excerto do Parecer de 2015 (busca garantir que o(a) egresso(a) dos cursos de formação inicial em nivel superior deverá, portanto, estar apto a:). No contexto do enunciado, isso significa que se espera que, com a implementação da proposta delineada no Parecer, ao final do curso, o egresso seja capaz de desempenhar uma determinada tarefa de forma satisfatória, relacionada à profissão docente. Tal entendimento remete ao conceito 
de competência, apresentado no Parecer de 2001, como vimos, cuja relação fica mais evidente se observamos os verbos utilizados na listagem.

Ao analisar os verbos da lista do Parecer de 2015, percebemos o uso predominante daqueles que expressam um procedimento ou uma ação ("atuar", "relacionar", "promover", "realizar", "utilizar", etc.), o que indica que o fazer prevalece na descrição do desempenho esperado do egresso. Bakhtin (2011, pp. 291-292) afirma que "quando escolhemos as palavras, partimos do conjunto projetado do enunciado, e esse conjunto que projetamos e criamos é sempre expressivo e é ele que irradia a sua expressão (ou melhor, a nossa expressão) a cada palavra que escolhemos".

Nessa ótica, a escolha desses verbos marca a intencionalidade dos enunciadores do Parecer que vai ao encontro da posição axiológica presente no Parecer de 2001, em que o conceito de competência aparece intimamente ligado à noção de "ação" e, portanto, ao "saber-fazer".

Cabe observar, todavia, que alguns verbos presentes na listagem do Parecer de 2015 expressam um fazer baseado em um domínio cognitivo, não se limitando apenas a um saber procedimental, como, por exemplo, os verbos "relacionar", "promover", "planejando", "avaliando", presentes nos itens (3), (4) e (6). Isso porque, como afirmam os enunciadores do Parecer CNE/CP n. 009/2001, é necessário que o egresso saiba mobilizar conhecimentos, transformando-os em ação (BRASIL, 2001, p. 29). Sob essa ótica, temos, então, aí mais um movimento de acolhimento do discurso das competências pelo Parecer de 2015. Vale lembrar que o conceito de competência presente no Parecer de 2001 considera o contexto da prática na mobilização das ações. E é isso que observamos nos fragmentos em análise do Parecer de 2015. Desse modo, a posição dos enunciadores do Parecer de 2015 reitera a percepção de formação do professor circunscrita à lógica do mercado de trabalho, presente nas Diretrizes revogadas, em que o essencial é a forma como o conhecimento é adquirido e aplicado.

Ao analisar os itens (1), (3), (4), (5) e (6), percebemos que o discurso dos enunciadores do Parecer CNE/CP n. 2/2015 entra em contato com o discurso alheio (Parecer CNE/CP n. 009/2001) e "penetra nele de dentro, introduz nele seus acentos e suas expressões, cria para ele um fundo dialógico" (BAKHTIN, 2014, p. 156).

Vemos que os temas abordados nesses itens têm a mesma orientação semântica (valorativa) da voz do Parecer de 2001: "atuação ética", "domínio das tecnologias de informação e comunicação", "relações de cooperação entre instituição educativa, família e comunidade", "consciência da diversidade", "participar na gestão das 
instituições de educação básica". Tais palavras pertencem aos enunciadores do Parecer de 2015, mas nelas ressoa a voz do Parecer de 2001 que define "as competências a serem desenvolvidas na formação da educação básica".

É relevante observar que as "competências" de 2001 assimiladas pelos enunciadores do Parecer CNE/CP n. 2/2015 nesses itens são aquelas que se alicerçam nos princípios éticos e políticos, envolvendo a dimensão social. Evidentemente, sendo um processo dinâmico, vivo, os enunciadores reorganizam o discurso da voz incorporada, as DCF.

No item (2), conforme os enunciadores do Parecer de 2015, a concepção de formação por eles proposta busca garantir que o egresso esteja apto a "dominar os conteúdos específicos e pedagógicos e as abordagens teórico-metodológicas". O Parecer de 2001, por sua vez, faz a abordagem a partir da ideia de que os professores deverão conhecer e dominar os "conteúdos básicos (...) que serão objeto da atividade docente". Percebemos que o Parecer de 2015 mantém, até certo ponto, uma relação dialógica de desacordo com o de 2001, mas não para negá-lo totalmente; antes, para ampliá-lo, já que apenas o "domínio dos conteúdos básicos" é insuficiente para o perfil almejado após a institucionalização do modelo proposto. Ademais, os enunciadores reiteram a importância do domínio do conteúdo de forma interdisciplinar, conforme destacado na competência definida no Parecer de 2001.

Do mesmo modo, no item (7), o Parecer de 2015 mantém com o Parecer de 2001 uma relação dialógica de complementação. Os enunciadores daquele Parecer reconhecem a importância da pesquisa na formação docente, mas ampliam a questão ao incentivarem que o professor seja autor da pesquisa pedagógica e científica ("utilizar instrumentos de pesquisa adequados para a construção de conhecimentos pedagógicos e científicos"), o que significa ir além de "utilizar resultado de pesquisas para o aprimoramento da sua prática" (grifos nossos).

Desse modo, no que se refere às temáticas abordadas nos itens (2) e (7), as palavras do Parecer de 2001 são "encontradas" pelos enunciadores do Parecer de 2015 a partir da sua visão valorativa, axiológica sobre o mundo, considerando o outro a quem se dirige o discurso e o contexto no qual se engendra a comunicação, (BAKHTIN, 2013). Ou seja, a voz do Parecer de 2001 que defende a formação para as competências aparece refletida e refratada no discurso dos enunciadores que fundamentam as NDCF.

De tudo que discutimos até aqui, podemos dizer que os discursos presentes no Parecer CNE/CP n. 2/2015 mantêm relação dialógica de convergência com o discurso da formação para as competências, professado no Parecer CNE/CP n. 009/2001, marcando o posicionamento valorativo dos enunciadores em relação 
ao tema. Em vários momentos, o discurso de tais enunciadores se entrelaça com o discurso do Parecer de 2001, fundindo-se com algumas vozes nele presentes, completando ou silenciando outras, atualizando, desse modo, sentidos sobre a formação docente.

\title{
3.2. A inter-relação com os discursos citados
}

O exame das vozes e discursos de pareceres do Conselho Nacional de Educação (CNE), convocados pelos enunciadores do Parecer CNE/CP n. 2/2015 para fundamentar o modelo de formação proposto, reforça nossa percepção de que há um posicionamento interessado de tais enunciadores com relação ao discurso da formação para as competências. Podemos constatar isso em dois momentos de uso do discurso citado no texto, na parte intitulada "Diretrizes Curriculares Nacionais para a Formação Inicial e Continuada dos Profissionais do Magistério: proposição".

Ao tratar da importância da garantia de base comum nacional para a melhoria da formação dos profissionais do magistério, os enunciadores do Parecer CNE/CP n. 2/2015 assim se posicionam:

\begin{abstract}
Assim, é importante que o projeto de formação se efetive em consonância com a base comum nacional e ao mesmo tempo garanta componentes curriculares, de natureza diversa, de modo a "instituir tempos e espaços curriculares diversificados como oficinas, seminários, grupos de trabalbo supervisionado, grupos de estudo, tutorias e eventos, atividades de extensão, entre outros capazes de promover e, ao mesmo tempo, exigir dos futuros professores atuações diferenciadas, percursos de aprendizagens variados, diferentes modos de organização do trabalho, possibilitando o exercício de diferentes competências a serem desenvolvidas". (Parecer $\mathrm{CNE} / \mathrm{CP}^{\circ}{ }^{\circ}$ /2001, p. 52)
\end{abstract}

Orientados pela perspectiva bakhtiniana, podemos afirmar que o discurso do Parecer de 2001, presente no fragmento, entra na construção sintática do discurso dos enunciadores do novo Parecer, compondo a sua unicidade, tornandose, consequentemente, "tema de um tema" (BAKHTIN/VOLOCHÍNOV, 2014, p.150). Nessa ótica, há, no fragmento, uma integração entre duas vozes sociais (discursos dos dois Pareceres) que determinam que os cursos de formação docente devem estabelecer relações com a base comum nacional e ao mesmo tempo possibilitar a existência de componentes curriculares de distintos formatos e perfis. Nessa relação dialógica, ganha relevância o conceito de competências.

Conforme a perspectiva bakhtiniana, o discurso citado é visto pelo sujeito discursivo como a enunciação de outra pessoa, completamente independente, originado de outro contexto enunciativo. Esse discurso é inserido pelo enunciador para ser ampliado, enaltecido, negado, reconstituído, rechaçado, etc. Trata-se, nesse 
caso, do discurso "internamente persuasivo" (BAKHTIN, 2014) que se submete aos nossos propósitos. Todavia, no caso do Parecer em análise, os enunciadores enquadraram o discurso do Parecer CNE/CP n. 09/2001 de modo compacto em seu texto, não apresentando nenhuma discussão, nenhum comentário acerca do que foi dito. Há apenas a inserção definitiva da voz do Parecer CNE/CP N. 9/2001, que se comporta como uma "palavra sagrada, exigindo uma repetição reverente", inibindo e bloqueando o pensamento dos sujeitos (BAKHTIN, 2011, 368).

Nesse sentido, a voz presente é acolhida, no fragmento, como "palavra autoritária", e, consequentemente, não cabem modificações, sendo aceita como um bloco fechado. Aceitar essa voz é aceitar que os cursos de formação de professores devem "instituir tempos e espaços curriculares diversificados", exigindo dos futuros professores atuações e modos de organização do trabalho diferenciados, com vistas a possibilitar o "exercício de diferentes competências".

Conforme Voloshinov (s.d, p.11) a simples seleção de um epíteto já é um ato de avaliação ativo. Assim, podemos dizer que o fato de os enunciadores do Parecer CNE/CP n. 2/2015 terem selecionado para o seu texto um fragmento contendo a proposição "exercício de diferentes competências" significa que tomaram uma certa atitude sobre o discurso da formação para as competências. Não uma atitude indiferente, mas uma "atitude efetiva e interessada", partindo de uma posição avaliativa (BAKHTIN, s.d, p. 50).

Essa "atitude efetiva e interessada" em torno dessa temática se manifesta também quando os enunciadores dialogam com o Parecer CNE/CES n. 15/2005 para explicar que a Prática como Componente Curricular (PCC) a ser efetivada ao longo do processo formativo não pode ser confundida com o estágio supervisionado:

Nessa direção, como vimos, prática como componente curricular a ser efetivada ao longo do processo formativo não se confunde com o estágio supervisionado. $\mathrm{O}$ Parecer CNE/CES n ${ }^{0}$ 15/2005 ratifica essa compreensão ao afirmar que

(...) a prática como componente curricular é o conjunto de atividades formativas que proporcionam experiências de aplicação de conhecimentos ou de desenvolvimento de procedimentos próprios ao exercício da docência. Por meio destas atividades, são colocados em uso, no âmbito do ensino, os conbecimentos, as competências e as habilidades adquiridos nas diversas atividades formativas que compõem o currículo do curso. As atividades caracterizadas como prática como componente curricular podem ser desenvolvidas como núcleo ou como parte de disciplinas ou de outras atividades formativas. Isto inclui as disciplinas de caráter prático relacionadas à formação pedagógica, mas não aquelas relacionadas aos fundamentos técnicocientíficos correspondentes a uma determinada área do conhecimento. Por sua vez, o estágio supervisionado é um conjunto de atividades de formação, realizadas sob a supervisão de docentes da instituição formadora, e acompanhado por profissionais, em que o estudante experimenta situações de efetivo exercício profissional. O estágio supervisionado tem o objetivo de 
consolidar e articular as competências desenvolvidas ao longo do curso por meio das demais atividades formativas, de caráter teórico ou prático. (BRASIL, 2015, p. 32, grifos nossos)

Detectamos no excerto duas vozes: a voz dos enunciadores do Parecer CNE/CP 2/2015 e a do Parecer CNE/CES n. 15/2005. A segunda voz apresenta-se realçada por meio de estratégia de recuo de texto e diminuição do tamanho da fonte. É interessante observar o uso do verbo "ratificar" no enunciado, empregado com sentido de validar o que foi declarado e que carrega significação que dá legitimidade a um discurso. Antes de incorporar em seu texto a voz do Parecer CNE/CES n. $15 / 2005$, os enunciadores apresentam, em discurso direto, um longo trecho do Parecer CNE/CP n ${ }^{\circ}$ 28/2001 que distingue a prática como componente curricular do estágio supervisionado. $\mathrm{O}$ trecho traz informações suficientes para esclarecer ao interlocutor a diferença entre os dois componentes. Todavia, mesmo o Parecer CNE/ CP n. 28/2001 deixando explícita a diferença entre os componentes curriculares, os enunciadores resolvem trazer para o texto fragmentos do Parecer CNE/CES n. $15 / 2005$, que abordam a questão do desenvolvimento de competências.

A incorporação da voz desse último Parecer propicia a retomada do discurso das competências, revelando, desse modo, mais uma vez, a "atitude efetiva e interessada" dos enunciadores em torno da questão. Tal voz é categórica ao afirmar que é por meio da Prática como Componente Curricular que são colocados em uso "os conhecimentos, as competências $e$ as babilidades adquiridos nas diversas atividades formativas" e que o estágio supervisionado visa "consolidar e articular as competências desenvolvidas ao longo do curso" (grifos nossos). Essa voz adere ao texto de modo compacto, incondicional, sem comentários, sem modificações, igualmente ao fragmento que analisamos anteriormente.

A transmissão do discurso do Parecer CNE/CES n. 15/2005 como uma unidade estanque evidencia que os enunciadores do Parecer CNE/CP n. 2/2015 aceitam a voz presente nesse enunciado como voz de autoridade. E aceitá-la é admitir os princípios da formação para as competências, os quais sugerem que não só as disciplinas "relacionadas aos fundamentos técnico-científicos" podem gerar conhecimentos, como também o espaço da prática que passa a ser valorado como produção de saberes. Tem-se, assim, no fragmento em análise, a valoração de componentes curriculares "próprios do momento do fazer", como enfatiza o Parecer CNE/CP 2008/2001 e o Parecer CNE/CP n. 009/2001.

Ademais, essa persistência em relacionar teoria e prática ("a prática como componente curricular é o conjunto de atividades formativas que proporcionam experiências de aplicação de conhecimentos ou de desenvolvimento de procedimentos próprios ao exercício da docência") decorre do conceito de 
competência, que, como vimos, só existe "'em situação" e, portanto, não pode ser aprendida apenas no plano teórico nem no estritamente prático (BRASIL, 2001, p. $30)$.

Por fim, os discursos oficiais mobilizados no interior do texto estabelecem com o discurso do Parecer CNE/CP n. 2/2015 uma "amálgama química", em que os enunciadores, ao tomá-los como "uma palavra sagrada" (BAKHTIN, 2011, 368), acabam assimilando a perspectiva de formação neles veiculada.

\section{CONSIDERAÇÕES FINAIS}

Neste trabalho, analisamos as relações dialógicas que se engendram no Parecer CNE/CP n. 2/2015, que apresenta as novas Diretrizes Curriculares Nacionais para a Formação Inicial e Continuada dos Profissionais do Magistério da Educação Básica (NDCF), focalizando o posicionamento valorativo dos enunciadores com relação ao discurso da formação para as competências. Sob a perspectiva dialógica da linguagem, subsidiada nos pressupostos teórico-metodológicos de Bakhtin e do Círculo, examinamos as relações que o Parecer CNE/CP n. 2/2015 estabelece no diálogo com o Parecer CNE/CP n. 009/2001 - que fundamenta as Diretrizes revogadas, e com os discursos oficiais que tratam da formação para as competências, mobilizados no texto.

No percurso do trabalho, realizamos o estudo em dois momentos correlacionados entre si: um orientado para as condições de produção do Parecer $\mathrm{CNE} / \mathrm{CP}$ n. 2/2015; outro, para a sua parte sócio-verbal na relação com as reflexões levantadas na primeira parte. $\mathrm{Na}$ análise, constatamos que os enunciadores do Parecer CNE/CP n. 2/2015 não pronunciam o termo "competência". Até mesmo a expressão "competências e habilidades", amplamente utilizada nos discursos oficiais, foi alterada para "informações e habilidades", em algumas situações, e "conhecimentos e habilidades", em outras, fato que sugere uma orientação polêmica, percebida também na omissão de termos ligados ao paradigma das competências.

Não obstante, analisando vozes e discursos presentes no Parecer, constatamos que tais enunciadores respondem favoravelmente ao discurso da formação para as competências a partir de três movimentos dialógicos, a saber: (i) acentuação valorativa dos princípios da formação para as competências, evidente na prescrição de que parte da formação do professor deve ocorrer em diferentes espaços escolares, enfatizando, desse modo, o conhecimento construído "na" e "pela" experiência, "em situação"; (ii) reenunciação de vozes e discursos presentes no 
conjunto das competências definidas no Parecer CNE/CP n. 009/2001, sobretudo as competências relacionadas ao comprometimento com os valores inspirados da sociedade democrática, ao domínio dos conteúdos a serem socializados, à compreensão do papel social da escola e ao conhecimento de processos de investigação; e (iii) assimilação da perspectiva de formação veiculada nos discursos oficiais que defendem o ensino por competência, convocados no texto para fundamentar aspectos do modelo de formação proposto.

Nas Diretrizes revogadas, estabelecidas pelo Parecer CNE/CP n. 009/2001, a concepção de competência é adotada "como norteadora tanto da proposta pedagógica, em especial do currículo e da avaliação, quanto da organização institucional e da gestão da escola de formação" (BRASIL, 2001, pp. 36-37). Nas novas Diretrizes, expressas no Parecer CNE/CP n. 2/2015, verificamos que o conceito de competência não é tomado como nuclear na orientação dos cursos de formação de professores, mas seus princípios nelas se mantêm vivos. Constatamos que o discurso do Parecer CNE/CP n. 2/2015 mantém convergência com o discurso do Parecer CNE/CP n. 009/2001, que tomou o conceito de competências como nuclear para a formação de professores, atualizando, no entanto, léxicos, expressões e formulações. Nesse sentido, não há, nas linhas mestras do Parecer CNE/CP n. 2/2015, um rompimento com o discurso da formação para as competências.

Enfim, diante da discussão, certificamos, conforme o pensamento bakhtiniano, que o discurso do Parecer CNE/CP n. 2/2015 se encontra com o discurso da formação para as competências e com ele participa numa interação viva e tensa. Isso porque todo objeto, como nos adianta Bakhtin (2014, p. 86), "já está desacreditado, contestado, avaliado, envolvido por sua névoa escura" ou, pelo contrário, "iluminado pelos discursos de outrem que já falaram sobre ele".

\section{AGRADECIMENTOS}

Agradecemos ao Conselho Nacional de Desenvolvimento Científico e Tecnológico (CNPq) pela concessão da bolsa de doutorado.

\section{REFERÊNCIAS BIBLIOGRÁFICAS}

ANFOPE (2001). Documento para subsidiar discussão na audiência pública regional. Recife, 21/03/2001. Disponível em: http://portal.mec.gov.br/cne/arquivos/pdf/Recife.pdf. Acesso em: 07 de nov. 2015 . 
BAKHTIN, M. M. VOLOCHÍNOV, V. N. (1929). Marxismo e filosofia da linguagem: problemas fundamentais do método sociológico na ciência da linguagem. Trad. Michel Lahud e Yara Frateschi Vieira. São Paulo: Hucitec, 2014.

BAKHTIN, M. M. (1963). Problemas da poética de Dostoiévski. Tradução do russo, notas e prefácio de Paulo Bezerra. 5 ed. Revista e ampliada. Rio de Janeiro: Forense Universitária, 2013.

BAKHTIN, M. M. (1934-1935). O discurso no romance. In: Questões de literatura e de estética: teoria do romance. Trad. Aurora F. Bernardini et al. 7 ed. São Paulo: Hucitec, 2014.

BAKHTIN, M. M. (1952-1953) Gêneros do discurso. In: BAKHTIN, M. Estética da criação verbal. Trad. Paulo Bezerra. 6. Ed. São Paulo: Martins Fontes, 2011.

BAKHTIN, M. M. (1970-1971). Apontamentos de 1970-1971. In BAKHTIN, M. Estética da criação verbal. 6.ed. Trad. Paulo Bezerra. São Paulo: Martins Fontes, 2011.

BAKHTIN, M. M. (1919/1921). Para uma filosofia do ato. Tradução de Carlos Alberto Faraco e Cristóvão Tezza da edição americana Toward a philosophy of the act. Austin: University of Texas press, 1993. Tradução destinada exclusivamente para uso didático e acadêmico. [s.d.].

BRAIT, Beth (2012). Estilo. In: BRAIT, Beth (org). Bakbtin: conceitos-chave. 5 ed. São Paulo: Contexto.

BRAIT, Beth (2008). Análise e teoria do discurso. In: BRAIT, Beth. Outros conceitos-chave. São Paulo: Contexto.

BRASIL (2001). Parecer CNE/CP 009/2001, de 8 de maio de 2001. Diretrizes Curriculares Nacionais para a Formação de Professores da Educação Básica, em nível superior, curso de licenciatura, de graduação plena. Brasília: Ministério da Educação. Disponível em: < http://portal. mec.gov.br/cne/arquivos/pdf/009.pdf>. Acesso em: 24 jun. 2015.

BRASIL (2015). Parecer CNE/CP 2/2015, de 9 de junho de 2015. Diretrizes Curriculares Nacionais para a Formação Inicial e Continuada dos Profissionais do Magistério da Educação Básica. Brasília: Ministério da Educação. Disponível em: < http://portal.mec.gov.br/index. php? option $=$ com_content $\&$ view $=$ article\&id $=21123 \&$ Itemid $=866>$. Acesso em: 07 de jul. 2015.

BRASIL (2015). Resolução CNE/CP 2/2015, de 1 de julho de 2015. Diretrizes Curriculares Nacionais para a Formação Inicial e Continuada dos Profissionais do Magistério da Educação Básica. Brasília: Ministério da Educação. Disponível em: < http://portal.mec.gov.br/index. php? option $=$ com_content $\&$ view $=$ article $\& i d=21123 \&$ Itemid $=866>$. Acesso em: 07 de jul. 2015.

CURY, Carlos Roberto Jamil (2006). Conselhos de Educação: fundamentos e funções. Revista Brasileira de Política e Administração da Educação, v.22, n.1, pp. 41-67. Disponível em: < http://seer.ufrgs.br/index.php/rbpae/article/view/18721/10944>. Acesso em: 06 de nov. 2015.

DELORS, J. et al. (1996). Educação: um tesouro a descobrir: relatório para a UNESCO da Comissão Internacional sobre Educação para o Século XXI. Tradução José Carlos Eufrázio. São Paulo: 
Brasília, DF; Cortez; UNESCO, 1998. Disponível em <http://ftp.infoeuropa. eurocid.pt/database/000046001-000047000/000046258.pdf> Acesso em: 27 de nov. 2015.

FREITAS, Helena Costa Lopes (2015). CNE discute Diretrizes para Formação de Professores. Disponível em: < http://formacaoprofessor.com/2015/04/05/cne-discute-diretrizespara-formacao-de-professores/> Acesso em: 13 de nov. 2015.

MAUÉS, Olgaíses Cabral (2003). Reformas Internacionais da educação e formação de professores. Cadernos de Pesquisa. n. 118, pp. 89-117.

MAUÉS, Olgaíses Cabral (2011). A política da OCDE para a educação e a formação docente. A nova regulação? Educação, Porto Alegre, v. 34, n. 1, pp. 75-85.

PERRENOUD, Philippe. (2000). Dez novas competências para ensinar. Porto Alegre: Artmed.

SHIROMA, Eneida Oto. A formação do professor-gestor nas políticas de profissionalização. Revista e-curriculum, São Paulo, v.7 n.2, $2011<$ http://revistas.pucsp.br/index.php/ curriculum $>$

VOLOSHINOV, V. N.; BAKHTIN, M. M (1926). Discurso na vida e discurso na arte: (sobre poética sociológica). Tradução do inglês: Carlos Alberto Faraco e Cristovão Tezza, para fins didáticos. Circulação restrita, 1926. [s.d.].

Recebido: 24/04/2016

Aceito: 18/11/2016 